\title{
Influence of Internals on Fluidized Bed Reduction of Iron Ore*
}

\author{
By Kazuyuki SAKURAYA, ${ }^{* *}$ Kōji KAMIYA** and Minoru TANAKA**
}

\begin{abstract}
Synopsis
To improve the contacting efficiency between reducing gas and iron ore particles in fluidized bed reduction, the effect of internals which were arranged in a 2-dimensional cold model was studied. In the case of the bed without internals, gas bubbles became large with increasing gas velocity, but gas bubbles were well dispersed and large size bubbles were not observed in the case of the bed with horizontal internals arranged in the form of equilateral triangle in the model.

Using a 2-dimensional reduction reactor which had the same dimension as the cold model, the effect of internals on the reduction rate of iron ore by $\mathrm{H}_{2}$ at $700^{\circ} \mathrm{C}$ under the same bubbling conditions as the cold model was studied. The effect of internals on the overall reduction rate was not significant.

From the relation of the height of bed, gas conversion ratio and the level where large bubbles appeared in the cold model, it was considered that the partial pressure of $\mathrm{H}_{2} \mathrm{O}$ in $\mathrm{H}_{2}$ almost approached to the equilibrium value of $\mathrm{FeO}-\mathrm{Fe}$ reduction before gas bubbles became large.
\end{abstract}

\section{Introduction}

Fluidized bed reactor has been applied not only to the fields of chemical engineering and non-ferrous metallurgy but also to the field of ferrous metallurgy, such as H-iron process, ${ }^{1-4)}$ HIB process, ${ }^{5)}$ and FIOR process. ${ }^{6-10)}$ Mixing of solid particles in a fluidized bed is mainly performed by gas bubbles, so the role of bubbles is very important, but the by-passing of reducing gas necessarily occurs the growth and coalescence of bubbles in the bed. Accordingly, it must be examined to prevent the decrease in utilization of reducing gas. It is considered that the control of the growth and coalescence of bubbles by inserting internals into a fluidized bed is effective to improve the contacting efficiency between gas and solid particles. In the case of the fluidized bed reduction of iron ore, it would be expected to increase the utilization of gas by inserting the internals into a fluidized bed.

Volk, et al. ${ }^{11)}$ reported the behavior of fluidized bed in which vertical pipe internals were arranged to obtain the basic data for scale-up.

Osberg, et al. ${ }^{12,13)}$ observed the fluidization of particles in the bed being inserted various internals, and they reported that in the reduction of iron ore by hydrogen, when cylindrical screen internals were inserted in the fluidized bed, the utilization of gas in the bed with internals was higher than that without internals in the range below $60 \%$-reduction, but the reason and detail on the relation between the utilization of gas and bubbles had not been explained.

To make clear these problems, the authors examined the effect of internals on the bubble formation and growth in a fluidized bed when iron ore particles were fluidized by nitrogen at room temperature in a glass model of 2-dimensional fluidized bed (2-dimensional cold model test). Then the reduction of iron ore by hydrogen was carried out by using the reducing reactor which had the same dimension as the cold model, and the relation between the utilization of gas and the bubble formation was examined from the comparison of the results of the cold model test and the reduction test.

\section{Apparatus and Procedure}

\section{Sample}

Samples used for the 2-dimensional cold model test and the reduction test were Hamersley hematite ore in the size range of $32 \sim 60$ mesh, which was ground, sieved, washed and dried. The chemical analysis of the sample is shown in Table 1.

\section{2-dimensional Cold Model Test}

Rectangular fluidized bed (length $96 \mathrm{~cm}$, width $16.5 \mathrm{~cm}$, thickness $1.5 \mathrm{~cm}$ ) of which glass plates were used for both sides was used for the 2-dimensional cold model test to observe the position of bubble formed and the size of bubble. The gas distributor having eight orifices of $2 \mathrm{~mm}$ diameter at $20-\mathrm{mm}$ intervals was arranged at a distance of $10 \mathrm{~cm}$ from the bottom of the model. In this test $0.3 \sim 1.5 \mathrm{~kg}$ of ore was held in the model and was fluidized by pure nitrogen. The position and diameter of bubble formed and the behavior of fluidization were examined by the photographs taken.

Considering the dispersion of gas bubbles and movement of iron ore particles, internals made of cylindrical vinyl chloride rods of $3 \mathrm{~cm}$ diameter and $1.5 \mathrm{~cm}$ thick were arranged in the lattice form with equilateral triangles as shown in Photo. 1, and were fixed in the model by an adhesive. The ore weight and flow rate of nitrogen in the test using internals were the same as these using no internals.

\section{Reduction Test}

A stainless steel reactor having the same dimension as the cold model was used for the reduction test. The experimental apparatus used is schematically

Table 1. Chemical analysis of Hamersley iron ore (\%).

\begin{tabular}{ccccccc}
\hline T. Fe & $\mathrm{FeO}$ & $\mathrm{CaO}$ & $\mathrm{SiO}_{2}$ & $\mathrm{Al}_{2} \mathrm{O}_{3}$ & $\mathrm{P}$ & $\mathrm{S}$ \\
\hline 65.07 & 0.64 & 0.058 & 3.42 & 2.04 & 0.056 & 0.008 \\
\hline
\end{tabular}




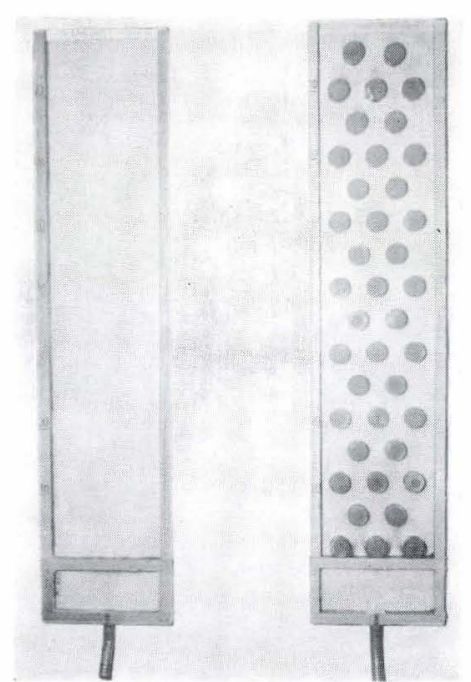

Photo. 1. 2-dimensional cold model.

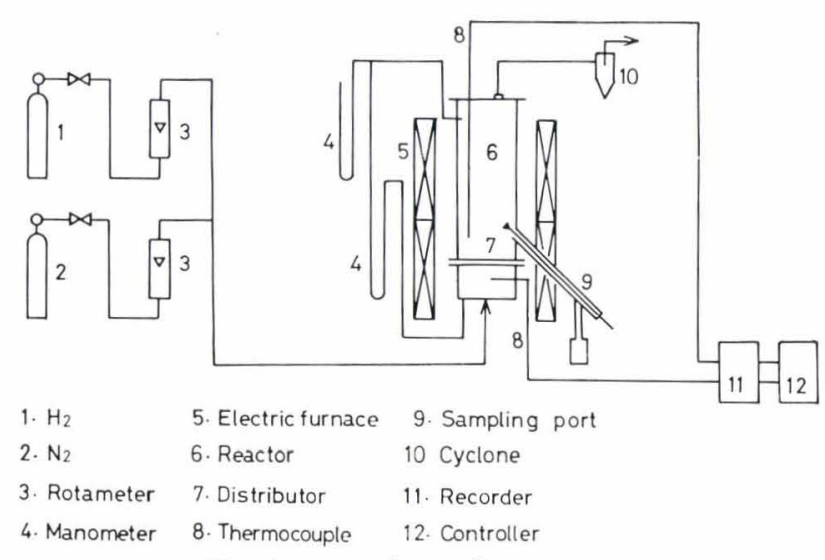

Fig. 1. Experimental apparatus.

shown in Fig. 1. Temperatures in the bed and the wind box were controlled constantly. The stainless steel gas distributor of $3-\mathrm{mm}$ thick having the same open area as that of the cold model was used. After temperature in the reactor was raised to a certain extent, nitrogen was passed into the reactor in order to replace air with nitrogen, then a certain amount of ore was charged. The charged ore was heated up to a certain temperature by fluidizing it with nitrogen. At a certain temperature, nitrogen was replaced with hydrogen and the reduction of iron ore was started. Fluidizing condition was estimated by the pressure drop through the fluidized bed and its fluctuations indicated by manometer. At constant intervals, a few grams of reduced iron ore were sampled from the bed and were stored in the flask filled with pure nitrogen to avoid reoxidation of the sample. The waste gas containing unreacted hydrogen, steam formed during reduction and dust was cleaned in the cyclone. The amount of dust collected in the cyclone was negligible as compared with that of the ore in the bed.

To examine the effect of internals, stainless steel internals having the same size as that of the cold model were inserted into the reducing reactor from upper part (Photo. 2).

To compare the effects for the cases of the bed with

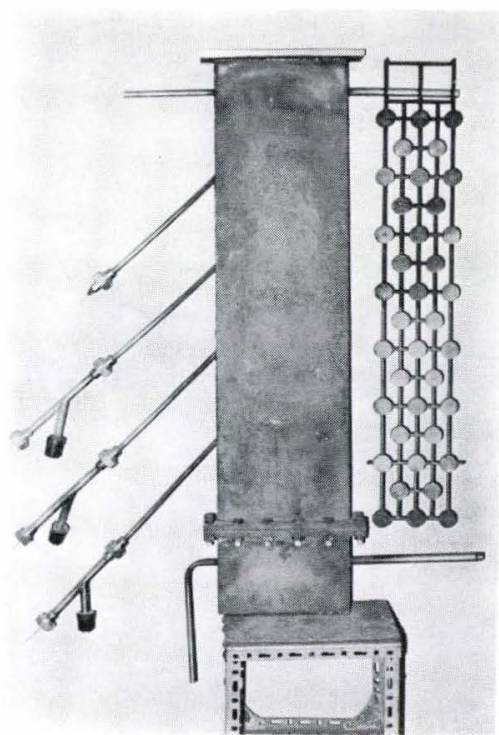

Photo. 2. Reactor for reduction and its internals.

and without internals, the iron ore was reduced under the same reduction conditions (temperature, amount of ore and flow rate of hydrogen). The reduction degree of the sample of reduced ore at constant intervals was determined by the reoxidation method.

\section{Results and Discussion}

\section{Cold Model Test}

The influence of internals on bubbles at various weight of bed and the superficial velocity $u_{o}$ are shown in Photos. 3 and 4. The minimum fluidizing velocity $u_{m f}$ of Hamersley iron ore particles (mean diameter $0.0354 \mathrm{~cm}$ ) with nitrogen at room temperature calculated from Eq. (1) was $19.5 \mathrm{~cm} / \mathrm{sec}$.

\section{Weight of Bed: $0.3 \mathbf{~ k g}$}

In the bed without internals, the gas passing through orifices of gas distributor spouted out of the upper part of the bed without lateral dispersion of gas and this spouting was extended with an increase in gas velocity. In the bed with internals, gas bubbles were observed at the position of about $2 \mathrm{~cm}$ above the gas distributor when $u_{o}$ was over $100 \mathrm{~cm} / \mathrm{sec}$, but the spouting of ore particles was supressed by internals.

\section{Weight of Bed: $0.5 \mathbf{~ k g}$}

In the case of the bed without internals, the bubble was started to form at the position of about $8 \mathrm{~cm}$ above the gas distributor. This position shifted downward and the height of bed became higher with an increase in gas velocity. In the case of the bed with internals, the behavior of bubble was the same as that without internals, but diameter of bubbles was not larger than the distance between internals and the bubbles were fairly uniformly dispersed in the bed.

\section{Weight of Bed: $1 \mathbf{k g}$}

In the case of the bed without internals, the position of bubble formation was about the same as that for the bed weighing $0.5 \mathrm{~kg}$, but the growth of gas bubbles became more active and larger bubbles were 


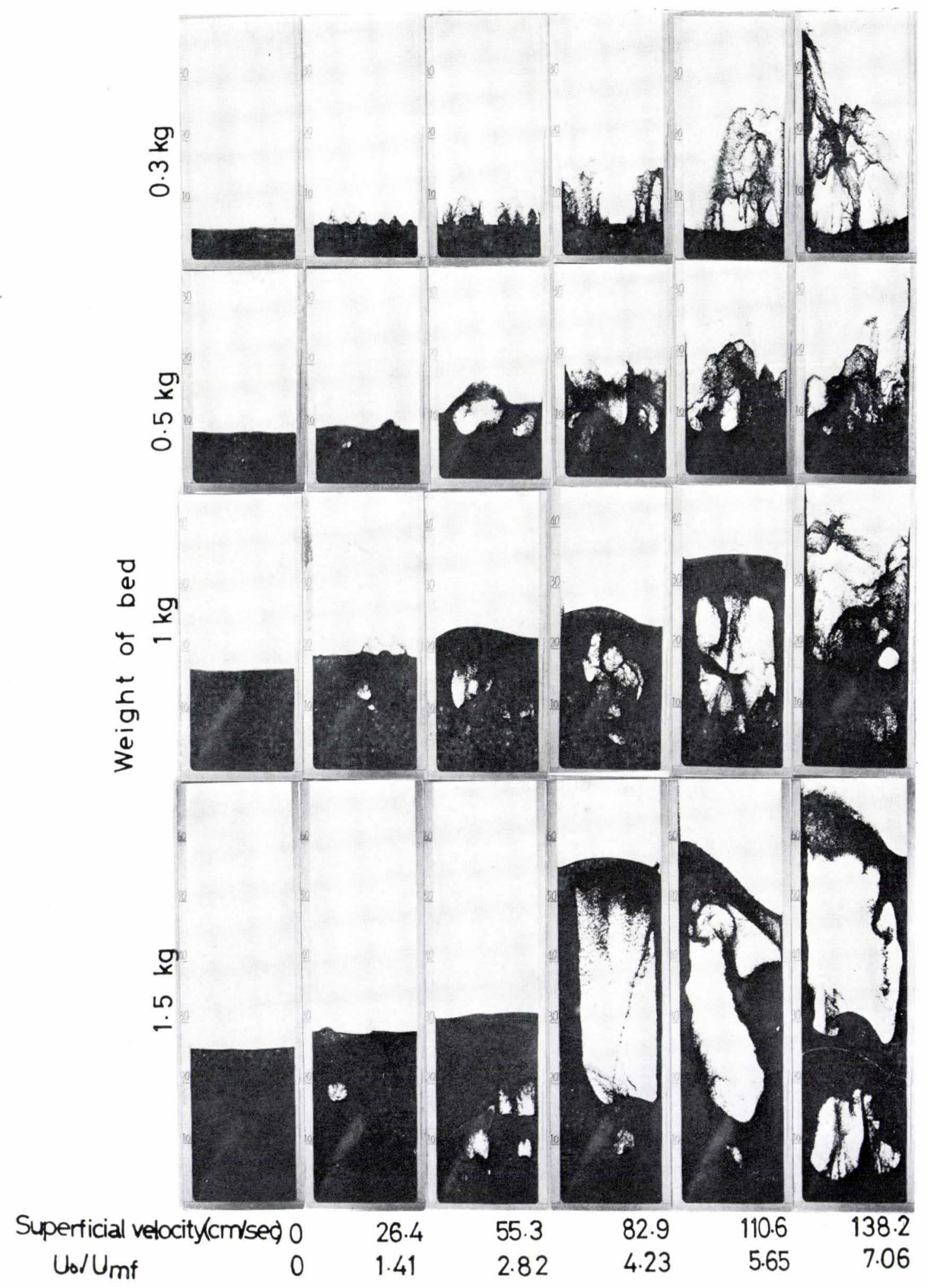

Photo. 3. Behavior of bubbles in the 2-dimensional cold model at various gas velocities.

observed at $u_{o}$ above $110.6 \mathrm{~cm} / \mathrm{sec}$. In the case of the bed with internals, the position of bubble formation shifted downward with an increase in flow rate of gas as compared with the case without internals, but the growth and coalescence of bubbles could not be observed. Even in the case of $u_{o}=138.2 \mathrm{~cm} / \mathrm{sec}$, the bubbles were controlled and were dispersed uniformly in the bed by internals and the diameter of bubbles was smaller than the distance between in- ternals.

\section{Weight of Bed: $1.5 \mathrm{~kg}$}

At $u_{o}$ above $82.9 \mathrm{~cm} / \mathrm{sec}$ the bubbles formed in the bed without internals grew to the width of the bed and the height of the bed increased, while the bubbles formed in the bed without internals were dispersed uniformly and the growth and coalescence of the bubbles was controlled by internals.

From the cold model test, the following was 


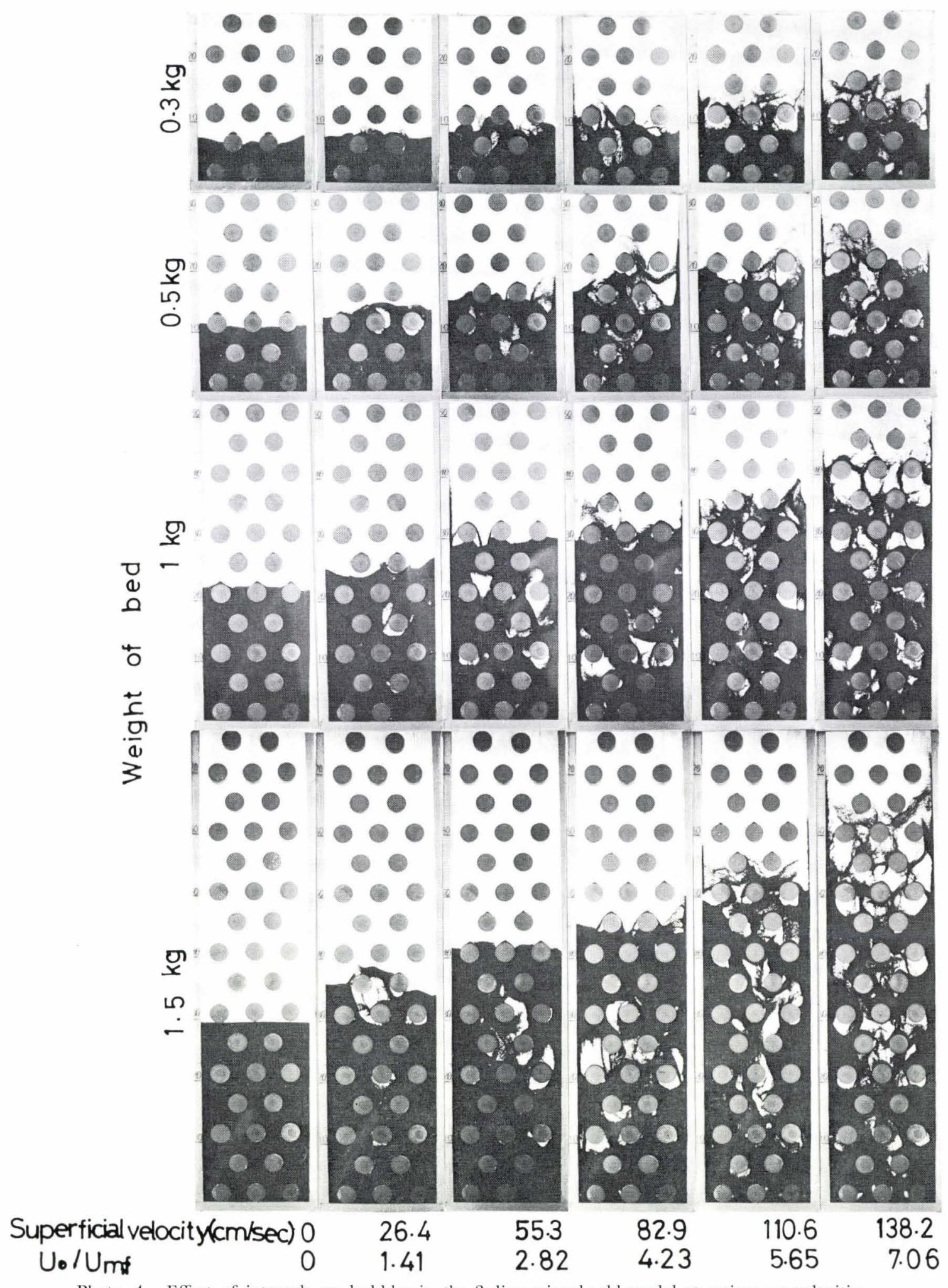

Photo. 4. Effect of internals on bubbles in the 2-dimensional cold model at various gas velocities.

proved:

(1) The bubbles were dispersed fairly uniformly in the bed by internals. This tendency became more pronounced with an increase in flow rate of gas.

(2) In the case of the bed without internals the position of bubble formation moved downward with an increase in gas velocity: In the bed with internals, bubbles formed just above the gas distributor and gas bubbles were dispersed finely throughout the bed.

If the reduction test is performed under the same condition as the cold model where the bubbles are dispersed finely by internals, the contact between gas and particles will be improved as compared with the case without internals, and the reduction rate will be increased by inserting internals. So, the reduction test was carried out under the conditions of higher flow rate of reducting gas and large amount of ore 
$\left(u_{0}=148 \mathrm{~cm} / \mathrm{sec}\right.$, ore weight $\left.=2.5 \mathrm{~kg}\right)$ by pure hydrogen at $700^{\circ} \mathrm{C}$.

\section{Correlation between Cold Model Test and Reduction Test}

As the fluidization of particles and behavior of bubbles in the bed cannot be observed directly in the reduction test, it is not easy to carry out the reduction test by keeping the same condition as that for the examination of the behaviors of particles and bubbles in the cold model test. So, the minimum fluidizing velocity $u_{m f}$ was adopted as a basic factor of the correlations between the cold model test and the reduction test.

From the physical properties of gas and particle, $u_{m f}$ is presented by the following equation. ${ }^{14}$ )

$$
\begin{aligned}
u_{m f}= & \frac{\mu}{d_{p} \rho_{g}} \\
& \times\left[\left\{(33.8)^{2}+0.0408 \frac{d_{p}^{3} \rho_{g}\left(\rho_{s}-\rho_{g}\right) g}{\mu^{2}}\right\}^{1 / 2}-33.7\right]
\end{aligned}
$$

where, $d_{p}$ : diameter of particle $(\mathrm{cm})$

$\rho_{g}, \rho_{s}$ : densities of gas and particle, respectively $\left(\mathrm{g} / \mathrm{cm}^{3}\right)$

$\mu: \quad$ viscosity of gas $(\mathrm{g} / \mathrm{cm} \mathrm{sec})$

$g$ : acceleration of gravity $\left(\mathrm{cm} / \mathrm{sec}^{2}\right)$

The fluidizations at the cold model and the reduction test can be compared by the ratio of $u_{o}$ to $u_{m f}$. If $u_{o} / u_{m f}>1$, gas corresponding to $\left(u_{o}-u_{m f}\right)$ was considered to be converted into bubbles and by-passed through the bed.

The changes in the minimum fluidizing velocities are shown in Fig. 2, considering the decrease in density of particle caused by the removal of oxygen during the progress of iron ore reduction. It was assumed that the change in diameter of particle by sintering and abrasion of ore during reduction did

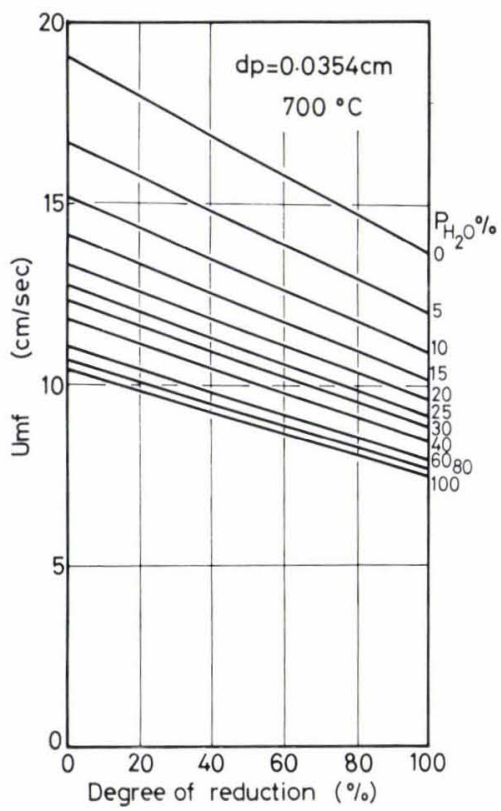

Fig. 2. Effect of $P_{\mathrm{H}_{2} \mathrm{O}}$ in hydrogen gas and degree of reduction on $u_{m f}$. not occur. The minimum fluidizing velocities were calculated from the change in concentration of steam formed by reduction, in the case that $d_{p}=0.0354 \mathrm{~cm}$ and reduction temperature $=700^{\circ} \mathrm{C}$. From the lack of experimental data on the viscosity of $\mathrm{H}_{2}-\mathrm{H}_{2} \mathrm{O}$ system, the viscosity was estimated from Wilke's equation. ${ }^{15)}$

Figure 3 shows the effects of $P_{\mathrm{H}_{2} \mathrm{O}}$ in hydrogen and degree of reduction on the ratio of $u_{o} / u_{m f}$ and the dotted line shows an example of the change in the ratio of $u_{o} / u_{m f}$ caused by the change in steam concentration in the bed at the batch reduction process. The value of $u_{o} / u_{m f}$ was always above 9 during reduction, while the value of $u_{o} / u_{m f}$ was below 7.06 in the cold model test, so it was considered that the bubble formation would be more active in the reduction test than the cold model test and the effect of internals would become more significant in the reduction test.

\section{Influence of Internals on Mixing of Ore Particles}

An increase in the value of (height of bed)/(cross sectional area of bed) causes a slugging bed and interrupts the mixing of particles in the bed. It seemed that the internals also interrupted the axial mixing of particles in the bed. In order to examine the mixing of particles in the bed, a difference in reduction degrees of the samples at three levels in the bed was measured. The sampling was carried out at fixed intervals from the sampling ports located at the positions of $15 \mathrm{~cm}, 30 \mathrm{~cm}, 45 \mathrm{~cm}$ above the gas distributor at the same time.

The reduction curves for the beds without and with internals are shown in Figs. 4 and 5, respectively. Without regard to the internals, a difference in reduction degrees of the samples at each level could not be observed and it was recognized that the particles in the bed with internals were mixed completely below the bed height of $45 \mathrm{~cm}$ at $u_{0}=148 \mathrm{~cm} / \mathrm{sec}$. As the reduction degree of ore at each level in the bed was the same at any given reduction time, in the following test the sampling was made from the port located

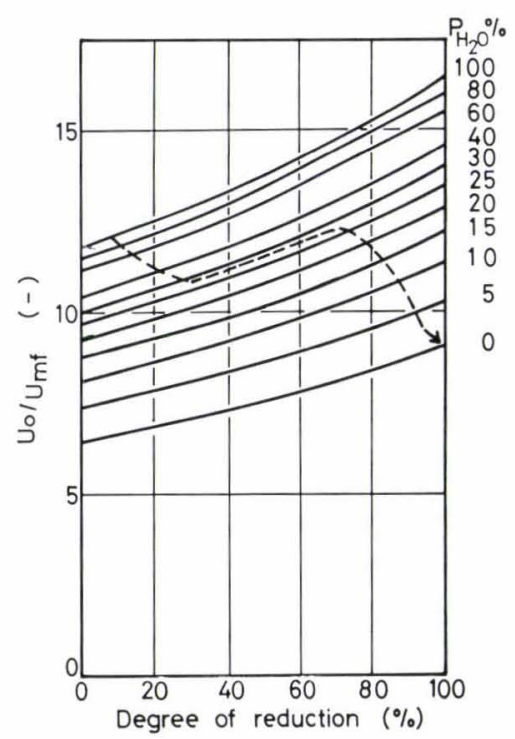

Fig. 3. Effect of $P_{\mathrm{H}_{2} \mathrm{O}}$ in hydrogen gas and degree of reduction on $u_{o} / u_{m f}$. 


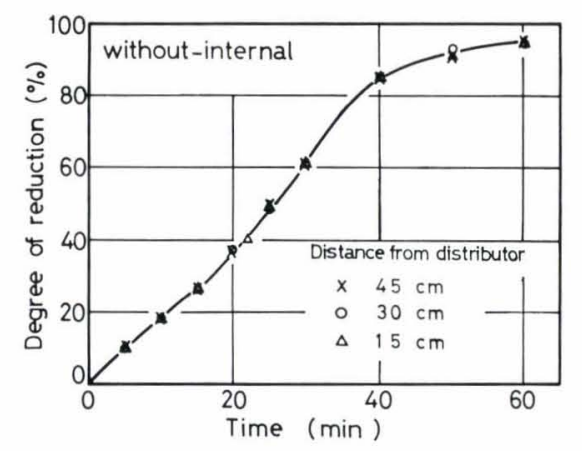

Fig. 4. Reduction curves by hydrogen at $700^{\circ} \mathrm{C}$.

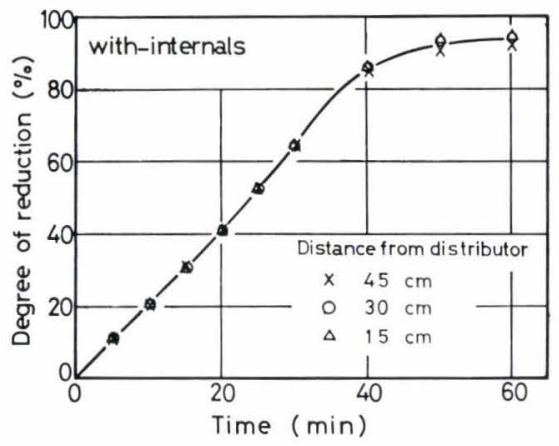

Fig. 5. Reduction curves by hydrogen at $700^{\circ} \mathrm{C}$.

at the position of $15 \mathrm{~cm}$ above the gas distributor.

\section{Influence of Internals on Reduction Rate}

In the reduction test under the conditions described above, the influence of internals on the reduction rate is shown in Fig. 6. Without regard to internals, the reduction rate with internals did not differ from that without internals and all of the reduction curves were almost coincident. So, the internals were not effective for the reduction rate of ore in this test.

This means that the formation and growth of bubbles have no influence on the reduction rate in a batch fluidized bed reduction by hydrogen at $700^{\circ} \mathrm{C}$ and this result conflicted with what was expected from the results of the cold model test.

\section{Relation between Height of Bed and Gas Conversion Ratio}

In order to make clear the reason why the difference of reduction rate by internals could not be observed in spite of lowering the contacting efficiency between gas and ore particles by the growth of bubbles, the following reduction test was carried out. Weight of bed was varied from $0.3 \mathrm{~kg}$ to $2 \mathrm{~kg}$ and the ore was reduced under a constant flow rate of hydrogen without internals. The change in the conversion ratio of hydrogen was examined at various height of the bed.

Reduction curves at various weight of the bed are shown in Fig. 7. Reduction rate increases with a decrease in weight of ore. Steam concentration in offgas from the fluidized bed can be calculated using the reduction degree and the flow rate of hydrogen.

The relation between the steam concentration, i.e., the gas conversion ratio and the reduction degree of

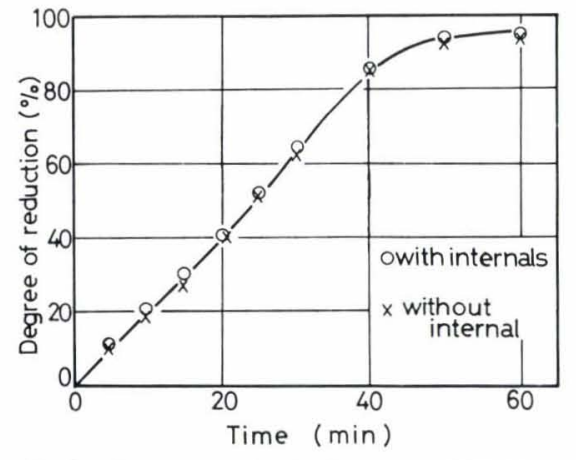

Fig. 6. Reduction curves by hydrogen at $700^{\circ} \mathrm{C}$. (weight of bed: $2.5 \mathrm{~kg}$, gas velocity: $148 \mathrm{~cm} / \mathrm{sec}$ )

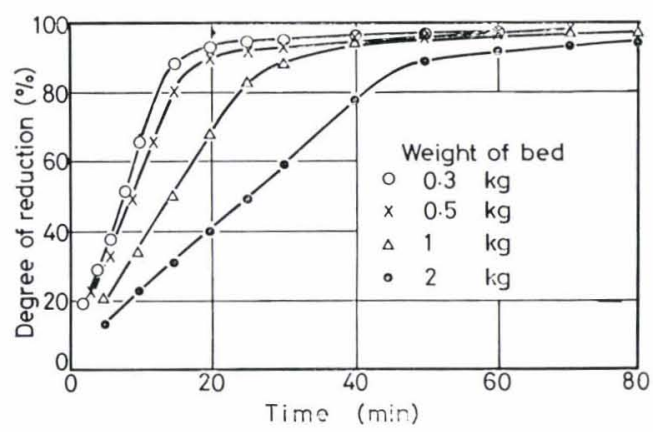

Fig. 7. Reduction curves by hydrogen at $700^{\circ} \mathrm{C}$. (gas velocity: $124.9 \mathrm{~cm} / \mathrm{sec}$ )

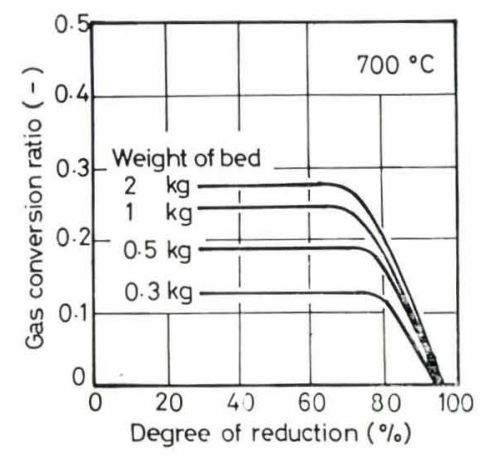

Fig. 8. Relation between gas conversion ratio and degree of reduction at various weight of bed.

ore particles at various weight of the bed are shown in Fig. 8. In the range of $20 \sim 70 \%$-reduction, as the reduction rate was mainly controlled by the amount of reducing gas supplied, the gas conversion ratio was maintained at constant level at any given weight of ore. Above $70 \%$-reduction, the gas conversion ratio decreased rapidly at any given weight of ore.

The relation between the height of the bed and the gas conversion ratio at various reduction degree is shown in Fig. 9. In the range of $20 \sim 70 \%$-reduction, an increase in gas conversion ratio became almost negligible at above the bed height of about $16 \mathrm{~cm}$, and the steam concentration approached to the equilibrium value of $\mathrm{FeO}-\mathrm{Fe}$ reduction at $700^{\circ} \mathrm{C}$. This means that the reduction by hydrogen is extremely rapid and is completed within the zone of 16 $\mathrm{cm}$ above the gas distributor. The ore particles in the zone above $16 \mathrm{~cm}$ were scarcely reduced due to the increase in amount of steam in hydrogen and the 


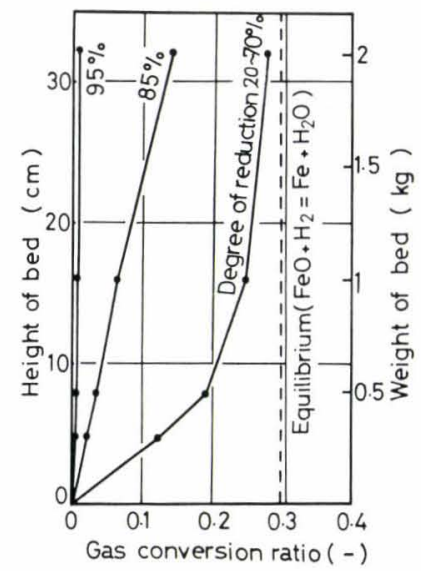

Fig. 9. Relation between height of bed and gas conversion ratio in hydrogen reduction at $700^{\circ} \mathrm{C}$.

decrease in reduction potential in the reducing gas. Therefore, the growth of bubbles in the zone above $16 \mathrm{~cm}$ had no influence on the reduction of ore particles. This fact is the reason that the internals had no effect on the reduction rate. In the range above $80 \%$-reduction, since the reduction proceeds in overall zone of the bed, it may be assumed that the effect of internals on the reduction rate can be observed. The progress of reduction of iron ore above $80 \%$-reduction, however, was slower than that in the range of $20 \sim 70 \%$-reduction due to the decrease in the amount of oxygen combined in the ore particles, so by-passing of hydrogen through the bed did not give a significant influence on the reduction rate in the range above $80 \%$-reduction, although hydrogen formed large bubbles. Consequently, a difference in reduction rate of the beds with and without internals was not obseved.

\section{Conclusion}

To improve the contacting efficiency between ore and reducing gas in the fluidized bed reduction, the effect of internals on the behavior of bubbles was studied by using the 2-dimensional cold model. The reduction test was carried out in the reduction furnace which had the same dimension as the cold model and the effect of internals on the reduction was also examined. The results obtained are as follows;
(1) In the 2-dimensional cold model test, while in the case of the bed without internals the bubbles grew by coalescence to the width of the bed, but in the case of the bed with internals the bubbles were dispersed by the internals and did not grow more than the distance between the internals.

(2) Reduction test by hydrogen at $700^{\circ} \mathrm{C}$ was carried out under the same condition as the cold model test or more vigorously bubbling condition than that. Without regard to the internals, a difference in reduction rate could not be observed. In the range of $20 \sim 70 \%$-reduction, the reaction between hydrogen and ore was so rapid that the steam concentration in the waste gas approached to the equilibrium value of $\mathrm{FeO}-\mathrm{Fe}$ reduction before the growth by coalescence of bubbles, so the reduction rate of ore was controlled by the amount of hydrogen supplied to the reactor. In the range above $80 \%$-reduction, because of a decrease in reduction rate in the bed, a difference in the reduction rates for the beds with and without internals was not distinguished.

\section{REFERENCES}

1) A. M. Squires and C. A. Johnson: J. Metals, 9 (1959), 586.

2) J. W. Traub: Iron Steel Eng., 37 (1960), 167.

3) R. A. Lubker and K. W. Bruland: J. Metals, 12 (1960), 321.

4) P. C. Keith, H. H. Stotler and R. J. MacMullan: Iron Steel Eng., 40 (1963), 95.

5) T. F. Reed, J. C. Agawal and E. H. Shipley: J. Metals, 12 (1960), 317.

6) J. W. Brown, D. L. Campbell, A. L. Saxton and J. W. Carr, Jr.: J. Metals, 18 (1966), 237.

7) R. J. Oehlberg: Iron Steel Eng., 51 (1974), 58.

8) Pat. Appl. No. 39- 19871.

9) D. C. Violetta: Rev. Mét., 72 (1975), 721.

10) D. C. Violetta: Rev. Mét., 72 (1975), 741

11) W. Volk, C. A. Johnson and H. H. Stotler: Chem. Eng. Prog., 58 (1962), 44.

12) J. P. Sutherland, G. Vassilatos, H. Kubota and G. L. Osberg: AIChE, 9 (1963), 437.

13) G. L. Osberg and T. A. Tweddle: Indust. Eng. Chem. Process Design and Development, 5 (1966), 87.

14) D. Kunii and O. Levenspiel: Fluidization Engineering, John Wiley \& Sons, New York, (1968), 73.

15) L. A. Bromley and C. R. Wilke: Indust. Eng. Chem., 43 (1951), 1641 . 